(c) Elsevier/INRA

Original article

\title{
Ethanol and acetic-acid tolerances in Drosophila melanogaster: similar maternal effects in a cross between 2 geographic races
}

\author{
M Chakir ${ }^{1}, \mathrm{P} \mathrm{Capy}^{1}, \mathrm{E} \mathrm{Pla}^{1}$, \\ J Vouidibio $^{2}$, JR David ${ }^{1}$ \\ 1 CNRS, Laboratoire de Biologie et Génétique Evolutives, \\ 91198 Gif-sur-Yvette, France; \\ 2 Faculté des Sciences, Laboratoire de Biologie des Populations, \\ Brazzaville, Congo
}

(Received 3 March 1993; accepted 14 October 1993)

\begin{abstract}
Summary - Ethanol and acetic-acid tolerances were studied in a cross between 2 geographic races of Drosophila melanogaster, ie a very sensitive population from equatorial Africa and a resistant French population. Average values in the $F_{1}$ and $F_{2}$ were similar and close to the mid-parent value. A clear maternal genotype effect was, however, observed for both traits between reciprocal $F_{1} s$, and the difference disappeared in the $F_{2}$. Further investigations demonstrated that for ethanol tolerance, the large difference between the parental strains was not entirely due to differences in their allelic frequencies at the $A d h$ locus. The possible mechanisms of these physiological variations are discussed.
\end{abstract}

ethanol tolerance / acetic-acid tolerance / ADH polymorphism / maternal genotype effect / geographic races

Résumé - Tolérances à l'éthanol et à l'acide acétique chez Drosophila melanogaster : effets maternels similaires dans un croisement entre 2 races géographiques. Les tolérances à l'éthanol et à l'acide acétique ont été étudiées, à partir d'un croisement entre 2 races géographiques de $\mathrm{D}$ melanogaster : une population très sensible d'Afrique équatoriale et une population française résistante. Les valeurs moyennes des générations $F_{1}$ et $F_{2}$ sont semblables et proches de la valeur du parent moyen. Une différence nette, due au génotype maternel, a été observée entre les $F_{1}$ réciproques. Cette différence disparaît en $F_{2}$. D'autres expériences ont montré que, pour la tolérance à l'éthanol, la grande différence observée entre les souches parentales n'est pas entièrement provoquée par la différence des fréquences alléliques observées au locus Adh. Les mécanismes possibles de ces variations physiologiques sont discutés.

tolérance à l'éthanol / tolérance à l'acide acétique / polymorphisme de l'ADH / effet du génotype maternel / races géographiques 


\section{INTRODUCTION}

Of the 8 species of the melanogaster subgroup, only Drosophila melanogaster presents a high alcohol tolerance. In this species, adaptation to resources with a high ethanol content is considered as a major ecological and evolutionary event (see David, 1977; Van Delden, 1982 ; Lemeunier et al 1986 ; David and Capy, 1988; Hoffman and Parsons, 1991). Ethanol tolerance is based on the presence of a very abundant alcohol dehydrogenase (ADH), and null mutants are very sensitive (David et al 1976). On the other hand, flies that are heterozygous for a null and a normal allele exhibit a normal tolerance (Kerver and Rotman, 1987). ADH is expressed at various levels in most developmental stages including embryos. It was recently demonstrated (Kerver and Rotman, 1987) that embryos that are heterozygous for a null allele exhibit different ethanol sensitivities in relation with the genotypes of the parents. When the functional allele was inherited from the female parent, embryonic tolerance was much better than when it was inherited through the sperm. However, this maternal effect disappeared in later stages.

Natural populations of $D$ melanogaster exhibit large variations in their ethanol tolerance, often arranged according to latitudinal clines (David and Bocquet, 1975; David et al, 1988). Among all the populations investigated so far, the most sensitive are found in equatorial Africa, which probably correspond to the ancestral populations of the species (David and Capy, 1988), with an $\mathrm{LC}_{50}$ of about $6 \%$ ethanol. Highly tolerant populations are found in temperate countries, and especially in Europe. In France, for instance, the average $\mathrm{LC}_{50}$ exceeds $17 \%$.

These differences in ethanol tolerance are accompanied by variations in allelic frequencies at the $A d h$ locus (David et al, 1986). More precisely, the more active $A d h-F$ allele is more abundant in temperate populations, while the less active $A d h-S$ allele predominates in tropical, sensitive populations. It has been repeatedly argued (see Van Delden, 1982, for a review) that a causal relationship existed between the 2 traits, and that the high ethanol tolerance was due to the higher frequency of the $A d h-F$ allele. However, this point was never correctly investigated in natural populations.

It was recently shown (Chakir et al, 1993) that acetic-acid and ethanol tolerances were always strongly correlated both at intra- and inter-specific levels. Morever, the 2 tolerances involve the same metabolic pathway, leading to the production of an increased amount of Acetyl-CoA. Acetic-acid tolerance, however, does not depend on the presence of active ADH.

These observations led us to investigate the genetic bases of ethanol and acetic-acid tolerances in crosses between African and European populations of $D$ melanogaster. The most interesting observation is a maternal effect, observed between reciprocal $\mathrm{F}_{1} \mathrm{~s}$ and disappearing in $\mathrm{F}_{2}$. Moreover, strains that are homozygous for the $A d h-F$ and $A d h-S$ alleles were extracted from the 2 types of natural populations. Significant differences were found between flies according to their geographic origins but not according to their $A d h$ genotypes. 


\section{MATERIAL AND METHODS}

Two geographic populations were compared. A French population was collected near Bordeaux. The other population was collected in the Congo, in a locality called Loua in the suburbs of Brazzaville (see Vouidibio et al, 1989, for a precise location). These 2 populations were polymorphic at the $A d h$ locus (left arm of chromosome 2 at 50.1, see Grell et al, 1965) but the frequencies of the 2 widespread alleles were highly different, according to the well-known latitudinal cline that occurs between Europe and tropical Africa (David et al, 1986). In Bordeaux, the frequency of $A d h-F$ was $94 \%$ while it was only $4 \%$ in Loua. Both populations were kept as mass cultures in laboratory bottles. More than 100 adults were transferred at each generation in order to avoid inbreeding and prevent laboratory drift. These mass populations were used in the toxicity tests.

Simultaneously, isofemale lines were established by isolating wild collected females in single vials. After larvae were observed, each female was checked for its $A d h$ genotype, and lines harboring the 2 alleles were conserved. From each initial line, several $F_{1}$ pairs were made and set in culture vials. After about 1 week, when offspring larvae were observed, the genotypes of the 2 parents were established by electrophoresis. From these $\mathrm{F}_{1}$ pairs, 2 selections were undertaken, in order to get homozygous lines for the $F$ or the $S$ allele. For example, for purifying the $F$ allele, the $F_{1}$ pairs with the highest $F$ frequencies were chosen, $F_{2}$ pairs were established, allowed to oviposit, checked for $A d h$ genotypes, and selected again if necessary. With this procedure, the required homozygous lines were obtained after 2, 3 or 4 generations. From the French population, from 8 wild living females, 8 homozygous $F F$ and $8 S S$ lines were available; from the Congolian population, 7 lines of each genotype were obtained from 7 wild females.

Ethanol and acetic-acid tolerances were measured according to previously described techniques (Chakir et al, 1993). Adults were grown at $25^{\circ} \mathrm{C}$ in bottles on a killed yeast food. Upon emergence they were lightly etherized and distributed in groups of 20 males or 20 females. After a recovery of $3-4 \mathrm{~d}$ on the same food, they were transferred to air-tight plastic vials containing experimental concentrations of ethanol or acetic acid. Dead flies were counted after $2 \mathrm{~d}$ and survival curves drawn separately for males, females and both sexes. The $\mathrm{LC}_{50}$ values (ie the concentrations killing $50 \%$ of the flies) were estimated graphically from each experiment.

ADH activity was measured on adult males aged $4 \mathrm{~d}$, according to Merçot and Higuet (1987). Activities are expressed as variation of optical density per $\mathrm{mg}$ of flies.

\section{RESULTS}

Ethanol and acetic-acid tolerances were measured on mass cultures from Bordeaux and Loua. Reciprocal $F_{1}$ and $F_{2}$ cultures were also investigated. When $L_{50}$ s are measured on the same strain over successive experiments, significant differences, due to unknown and uncontrolled variations, may be observed (Chakir et al, 1993). It is thus necessary to repeat the measurements several times on the same strain in order to calculate an average value for the parental strains and progeny. Mean $\mathrm{LC}_{50}$ s and numbers of repeats are given in table $\mathrm{I}$. 


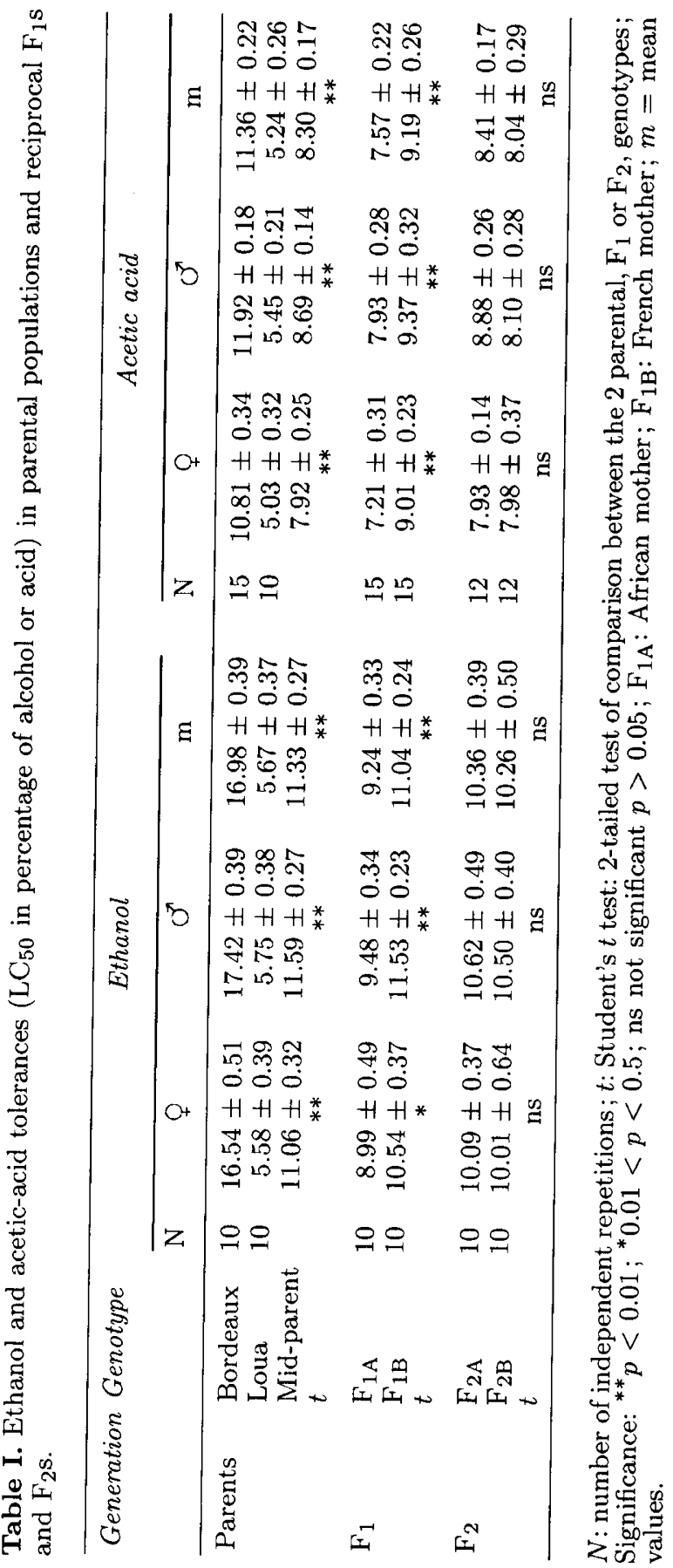


The ethanol tolerance (mean of both sexes) was on the average $17 \%$ in Bordeaux and $5.7 \%$ in Loua. The difference $(11.3 \%)$ is highly significant. A slight, non-significant difference exists between sexes, and the males are a little more tolerant than the females. This sex difference became significant when all the data (parents, $F_{1}$ and $F_{2}$ ) were considered simultaneously. $F_{1}$ flies exhibit an intermediate tolerance $(10.1 \%)$ which is not statistically different from the mid-parent value $(11.33 \pm 0.27 \%)$. The reciprocal $\mathrm{F}_{1} \mathrm{~s}$ are, however, significantly different (see table $\mathrm{I})$, and the flies from a Bordeaux mother $\left(\mathrm{F}_{1 \mathrm{~B}}\right)$ are more tolerant than those from an African mother $\left(F_{1 A}\right)$. In such a case, male and female progeny must be analysed separately, since females are genetically identical while males inherit their $\mathrm{X}$ chromosome from their mother. Table I shows that males of the reciprocal $\mathrm{F}_{1} \mathrm{~s}$ are clearly different $(d=2.05 \pm 0.41 \%$ alcohol $)$, and the direction of the difference agrees with the mother's characteristics. A similar observation is also valid for females $(d=1.5 \pm 0.60 \%)$. The difference is a little smaller than in males, but not significantly so. The reciprocal $\mathrm{F}_{2} \mathrm{~s}$ are almost identical and the mean value (both sexes pooled) of $10.32 \pm 0.48 \%$ is similar to the average $F_{1}$ s and not different from the mid-parent value. All these observations demonstrate that the difference between the reciprocal $F_{1} s$ is mostly due to a maternal genotype influence which persists until the adult stage but totally disappears in the $\mathrm{F}_{2} \mathrm{~s}$.

For acetic-acid tolerance the results are quite similar (table I). The difference between the parental strains $(6.1 \%)$ is less pronounced than for ethanol, but still highly significant with no overlap of the distributions. A general tendency also exists for the males to be a little more tolerant than the females. The reciprocal $\mathrm{F}_{1} \mathrm{~s}$ are statistically different and the difference is the same in females and males. This difference disappears in the reciprocal $\mathrm{F}_{2} \mathrm{~s}$. The mean values of the $\mathrm{F}_{1} \mathrm{~s}(8.38 \%)$ and $\mathrm{F}_{2} \mathrm{~s}(8.23 \%)$ are also very close to the mid-parent $(8.31 \%)$. The occurrence of a maternal genotype effect, disappearing in the $\mathrm{F}_{2} \mathrm{~s}$, is also a valid interpretation.

The experiments described above were performed with mass cultures, polymorphic for the 2 alleles at the $A d h$ locus. ADH is a key enzyme for ethanol detoxification, and the most active allele $(A d h-F)$ was present with a high frequency $(94 \%)$ in the Bordeaux population but with a very low frequency $(4 \%)$ in the Loua population. The big difference in ethanol tolerance between these 2 populations could be due to this difference in allelic frequencies. To check this hypothesis, homozygous $F F$ and $S S$ lines were extracted from each natural population (see Materials and Methods) and ethanol tolerances measured. These results are shown in figure 1 and the statistics are given in table II.

A broad variability is evidenced between lines, and this may be due to the high inbreeding which occurred during the process of purifying the homozygous lines. The phenomenon is relatively more pronounced among the Congolian lines, with coefficients of variation around $35 \%$. No significant differences exist according to the $A d h$ genotype. On the other hand, there is no overlap of the values between French and Congolian lines and the differences according to geographic origins are highly significant. A final observation is that the mean values in table II are somewhat superior to those of the parental lines in table I, but the differences are not significant. Acetic-acid tolerance was not measured in these lines since this trait does not depend on the presence of an active ADH (Chakir et al, 1993). It remained possible that, in spite of having the same electrophoretic allele and the same protein 


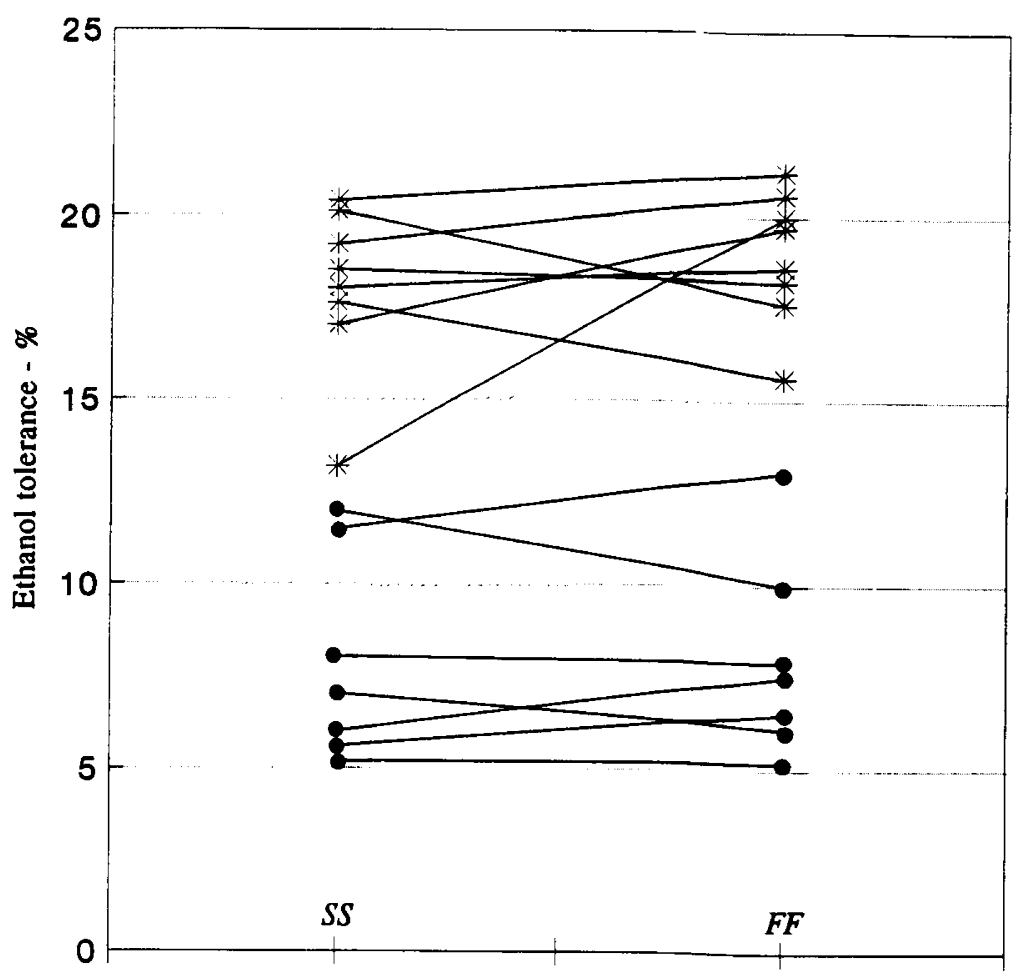

Adh genotypes

Fig 1. Ethanol tolerance in Congolian and French lines, homozygous for the $F$ or $S$ allele of the $A d h$ locus. Strains extracted from the same heterozygous wild collected female are joined by a line. $\bullet$ : Congo; *: France.

(see Kreitman, 1983), African strains could have a lower ADH activity due to different genetic regulations. To check this hypothesis, the homozygous strains from the same geographic area were pooled in a single mass culture, and ADH activity measured on males. The results in table II clearly show that this was not the case: the well-known difference between $F$ and $S$ alleles was confirmed. No difference was found, however, between French and Congolian flies with the same allele.

\section{DISCUSSION AND CONCLUSION}

Two main conclusions may be drawn from this work. First, the large difference that exists between the ethanol tolerance of the French and equatorial African populations of $D$ melanogaster is correlated with a difference in $A d h$ allelic frequencies (David et al, 1986) but is not entirely due to this genetic divergence. Moreover, the large difference in $\mathrm{ADH}$ activity which exists between the $F$ and $S$ allele does not completely explain the variations in ethanol tolerance. Obviously, at least when we 
Table II. Ethanol tolerance and ADH activity in French and Congolian flies that are homozygous for the Adh $F$ or $S$ alleles.

\begin{tabular}{|c|c|c|c|c|c|}
\hline \multirow[t]{2}{*}{ Population } & \multirow[t]{2}{*}{ Genotype } & \multicolumn{3}{|c|}{ Tolerance } & \multirow[t]{2}{*}{ ADH activity } \\
\hline & & $m \pm s e$ & $\mathrm{CV} \%$ & $\mathrm{~N}$ & \\
\hline France & $\begin{array}{l}\text { FF } \\
\text { SS } \\
\text { Comp }(t)\end{array}$ & $\begin{array}{c}18.94 \pm 0.64 \\
18.00 \pm 0.80 \\
\text { ns }\end{array}$ & $\begin{array}{r}9.6 \\
12.6\end{array}$ & $\begin{array}{l}8 \\
8\end{array}$ & $\begin{aligned} 28.11 & \pm 1.54 \\
9.83 & \pm 0.60 \\
& * *\end{aligned}$ \\
\hline Congo & $\begin{array}{l}\text { FF } \\
\text { SS } \\
\text { Comp }(t)\end{array}$ & $\begin{array}{c}7.79 \pm 1.08 \\
7.90 \pm 1.06 \\
\text { ns }\end{array}$ & $\begin{array}{l}36.6 \\
35.3\end{array}$ & $\begin{array}{l}7 \\
7\end{array}$ & $\begin{aligned} 27.74 & \pm 2.51 \\
9.74 & \pm 0.57 \\
* * & \end{aligned}$ \\
\hline
\end{tabular}

$m \pm$ se: mean and standard error; $C V$ : coefficient of variation between lines; $N$ : number of lines; comparisons are made with Student's $t$ test. Significance: ${ }^{* *} p<0.01$; ns not significant. For ADH activity measurements, the lines harboring the same allele were pooled, and 4 repetitions were made on each genotype.

compare geographically distant populations, ethanol tolerance is mainly mediated by a different, but still unknown, physiological process. This was already suggested by Middleton and Kacser (1983) and David et al (1989). One mechanism could be that the sensitivity of the target organs, ie the nervous system, is very different between European and Congolian flies. But another mechanism is that ethanol tolerance could depend not only on ADH activity, but also on ACS (Acetyl-CoAsynthetase) activity. This possibility, which was excluded for larvae by Freriksen et al (1991), seems worth consideration for adults according to the work of Chakir et al (1993). Obviously, this problem deserves further investigation.

A second, and novel, conclusion is the magnitude of a maternal effect which discriminates the reciprocal $F_{1} s$, and also the fact that this effect concerns both acetic-acid and ethanol tolerances.

Various processes may explain maternal influences, including the transmission of cytoplasmic organelles (Sager, 1977) or symbionts (Nardon, 1993), a perturbation of the mother's physiology by environmental effects (David, 1962) or the asymmetric contribution of paternal and maternal genotypes to the formation of the embryo (see Lawrence, 1992).

Our observations are probably explained by this last type, ie maternal genotype effect. The most striking observation is that physiological differences between reciprocal $F_{1} s$, which are initiated in the embryo, persist until the adult stage. By contrast, maternal effects on $\mathrm{ADH}$ activity, described by Kerver and Rotman (1987), disappeared much earlier in the larval stages. We do not know which metabolic pathway is involved in the maternal influence observed in crosses between European and Afrotropical flies. The similarity between ethanol and acetic-acid tolerances suggests that the ACS activity could be involved. But the tolerance of the target organs, especially of the nervous system, could also be modified (David et $a l, 1989)$. In conclusion, the large difference in ethanol tolerance between European and African flies may be partly due to differences in $\mathrm{ADH}$ activity and $A d h$ 
polymorphism. Natural selection, however, may also use other as yet unidentified processes, for increasing the difference, as evidenced in this paper.

\section{REFERENCES}

Chakir M, Peridy O, Capy P, Pla E, David JR (1993) Adaptation to alcoholic fermentation in Drosophila: A parallel selection imposed by environmental ethanol and acetic acid. Proc Natl Acad Sci USA 90, 3621-3625

David JR (1962) Les effets prolongés: Retentissement passager du milieu sur l'hérédité des organismes. Année Biol 1, 175-194

David JR (1977) Signification d'un polymorphisme enzymatique: la déshydrogénase alcoolique. Ann Biol 16, 451-472

David JR, Bocquet C (1975) Similarities and differences in latitudinal adaptation of two Drosophila sibling species. Nature 256, 588-590

David JR, Capy P (1988) Genetic variation of Drosophila melanogaster natural populations. Trends Genet 4, 106-111

David JR, Bocquet C, Arens MF, Fouillet P (1976) Biological role of alcohol dehydrogenase in the tolerance of Drosophila melanogaster to aliphatic alcohols: utilization of an ADH-null mutant. Biochem Genet 14, 989-997

David JR, Merçot H, Capy P, McEvey SF, Van Herrewege J (1986) Alcohol tolerance and $A d h$ gene frequencies in European and African populations of Drosophila melanogaster. Genet Sel Evol 18, 405-416

David JR, Alonso-moraga A, Capy P, Munoz-serrano A, Vouidibio J (1989) Short-range genetic variations and alcoholic resources in Drosophila melanogaster. In: Evolutionary Biology of Transient Unstable Populations, (A Fontdevila, ed) Springer Press, Berlin, 130-144

Freriksen AD, Seykens W, Scharloo, Heinstra PWH (1991) Alcohol dehydrogenase controls the flux from ethanol to lipids in Drosophila larvae. J Biol Chem 266, 21399-21403

Grell EH, Jacobson KB, Murphy JB (1965) Alcohol dehydrogenase in Drosophila melanogaster isozymes and genetic variants. Science 149, 80-82

Hoffmann AA, Parson PA (1991) Evolutionary Genetics and Environmental Stress. Oxford Univ Press, Oxford

Kerver WJM, Rotman G (1987) Development of ethanol tolerance in relation to the alcohol dehydrogenase locus in Drosophila melanogaster. II. The influence of phenotypic adaptation and maternal effect on survival on alcohol-supplemented media. Heredity 58, 239-248

Kreitman M (1983) Nucleotide polymorphism at the alcohol dehydrogenase locus in Drosophila melanogaster. Nature 304, 412-417

Lawrence PA, (1992) The Making of a Fly. Blackwell, Oxford

Lemeunier F, David JR, Tsacas L, Ashburner M (1986) The melanogaster species group. In: The Genetics and Biology of Drosophila Vol 3. (M Ashburner, Carson HL, JN Thompson, eds). Academic Press, New York, 147-256

Merçot H, Higuet D (1987) ADH activity in two Drosophila melanogaster strains from selection on body weight. Dros Inf Serv 66, 98-99 
Middleton RJ, Kacser H (1983) Enzyme variation, metabolic flux and fitness: alcohol dehydrogenase in Drosophila melanogaster. Genetics 105, 633-650 Nardon P (1993) Symbiose et évolution. Ann Soc Entom France 29, 113-140 Sager R (1977) Cytoplasmic inheritance. In: Cell Biology: A Comprehensive Treatise Vol 1. (L Goldstein, D Drescott, eds). Acad Press, New York, 279-317 Van Delden W (1982) The alcohol dehydrogenase polymorphism in Drosophila melanogaster. Selection at an enzyme locus. Evol Biol 15, 187-222

Vouidibio J, Capy P, Defaye D, Pla E, Sandrin J, Csinck A, David JR (1989) Shortrange genetic structure of Drosophila melanogaster populations in an Afrotropical urban area, and its significance. Proc Natl Acad Sci USA 86, 8442-8446 